\title{
A Meteorological Tower Based Wind Speed Prediction Model Using Fuzzy Logic
}

\author{
${ }^{1}$ Sardar Maran Poongavanam and ${ }^{2}$ Ponnusamy Ramalingam \\ ${ }^{1}$ Centre for Earth and Atmospheric Sciences, Sathyabama University, Chennai, India \\ ${ }^{2}$ Madha Engineering College, Kundarathur, Chennai, India
}

Received 2013-01-09, Revised 2013-02-12; Accepted 2013-05-07

\begin{abstract}
A number of wind speed prediction methods are available for estimating wind energy availability. In recent years there is a lot of research works carried out to predict wind speed by using mathematical and soft computing techniques. In this study the wind speed profile at different heights are predicted with the available meteorological tower data. The wind speed data at $02,08,16,32$ and $50 \mathrm{~m}$ levels of a meteorological tower is used to predict and develop fuzzy logic model beyond the height of the 50 meter tower. The experimental research gives the best performance for the wind speed prediction at various heights.
\end{abstract}

Keywords: Wind Speed, Wind Energy, Fuzzy Logic, Neural Network

\section{INTRODUCTION}

The needs for energy, shortages of fossil fuelled energy, the environmental effects and air pollution due to the greenhouse gas emission and global warming are all the factors that cause the use of renewable energy resources in the world. Some renewable energy resources such as wind and solar systems have the advantages of low operating costs while having much capital costs. These renewable resources will have considerable share in future provision of energy demand in several countries (Javadi and Hojjatinia, 2012).

Wind energy is one of the most promising alternative energy technologies of the future. Throughout recent years, the amount of energy produced by wind-driven turbines has increased exponentially due to significant breakthroughs in turbine technologies, making wind power economically compatible with conventional sources of energy (Sreedevi and Paul, 2011; Badran et al., 2011). Due to increasing demand for renewable energy resources, wind energy and its associated issues have received more attention recently (Hossain et al., 2009; Ata and Kocyigit, 2009). The power-generating efficiency of a wind turbine can be significantly increased if the turbine's operation is controlled based on the information of wind and wind changes at the turbine location (Badran et al., 2011). There are various methods in soft computing techniques are available for the predication of wind speed namely Artificial Neural Network, Numerical Weather Prediction and Fuzzy Logic (Mohandes et al., 2011; Hocaoglu et al., 2009).

India has the fifth largest installed wind power capacity in the world. Wind power accounts for $6 \%$ of India's total installed power capacity and it generates $1.6 \%$ of the country's power. It is estimated that $6 \mathrm{GW}$ of additional wind power capacity will be installed in India by 2012 , taking the total installed capacity beyond $15 \mathrm{GW}$.

\subsection{Study Area}

The wind speed data for this model is collected from 50 metre Instrumented Meteorological Tower located at Sathyabama University, Chennai, India with Latitude 12.9 $\mathrm{N}$ and Longitude $80.0 \mathrm{E}$. The wind speed data at the heights of $8 \mathrm{~m}, 16 \mathrm{~m}$ and 32 metre were taken into account for the fuzzy model. Total records of 52560 rows were selected for this study. From these 41621 records were selected for final fuzzy logic simulation model.

Corresponding Author: Sardar Maran Poongavanam, Centre for Earth and Atmospheric Sciences, Sathyabama University, Chennai, India 


\section{MATERIALS AND METHODS}

\subsection{Fuzzy System Modeling}

The past few years have witnessed a rapid growth in the number and variety of applications of fuzzy logic. Fuzzy logic, among the various available Artificial Intelligence techniques, emerges as an advantageous technique in predicting future events. (Perez et al., 2010).

Fuzzy logic is a research area based on the principles of approximate reasoning and computational intelligence. It uses soft linguistic variables (e.g., Very low, Low, Normal, High, Very high) and a continuous range of truth values, thus making a deviation from classical sets, logic and strict boolean decisions and assignments (Damousis et al., 2004). Fuzzy models are employed in cases where a system is difficult to model exactly or when ambiguity and vagueness is encountered in the problem formulation (Azouz et al., 2010). A typical fuzzy system comprises the following key parts: a rule base containing a number of IF-THEN rules, a decision-making unit, which performs the inference operations of the rules, the fuzzification interface which transforms crisp inputs into fuzzy sets that are processed by the fuzzy interface unit and the defuzzification interface, that transforms the fuzzy conclusion providing a crisp output.
The fuzzy logic approach seems very suitable for dealing with uncertainty phenomena; although the use of probabilistic techniques was higher than the use of fuzzy techniques for safety issues also recommend to the researchers to use the fuzzy set technologies if the study must deal with vague knowledge or needs to communicate with the user in a more humanlike way.

Advantages of Fuzzy Logic as follows:

- Fuzzy Logic is a conceptually easy to understand. The mathematical concepts behind fuzzy reasoningare very simple. Naturalness of the approach makes it preferable to the other techniques

- Fuzzy logic is flexible, tolerant of imprecise data and it can model nonlinear functions of arbitrary complexity

Table 1. Input variable membership functions

\begin{tabular}{llllll}
\hline $\begin{array}{l}\text { Input } \\
\text { variables }\end{array}$ & Very low & Low & Normal & High & Very high \\
\hline WS08m & $0.0-1.0$ & $1.0-2.5$ & $2.5-6.0$ & $6.0-9.0$ & $9.0-12.0$ \\
WS16m & $0.0-1.0$ & $1.0-3.8$ & $6.0-7.0$ & $9.0-10.3$ & $11.0-14.0$ \\
\hline
\end{tabular}

Table 2. Output variable membership functions

\begin{tabular}{llllll}
\hline $\begin{array}{l}\text { Output } \\
\text { variable }\end{array}$ & Poor & Marginal & Average & Good & Excellent \\
\hline WS32m & $0.0-3.5$ & $3.5-6.5$ & $6.5-9.5$ & $9.5-12.5$ & $12.0-15.0$ \\
\hline
\end{tabular}

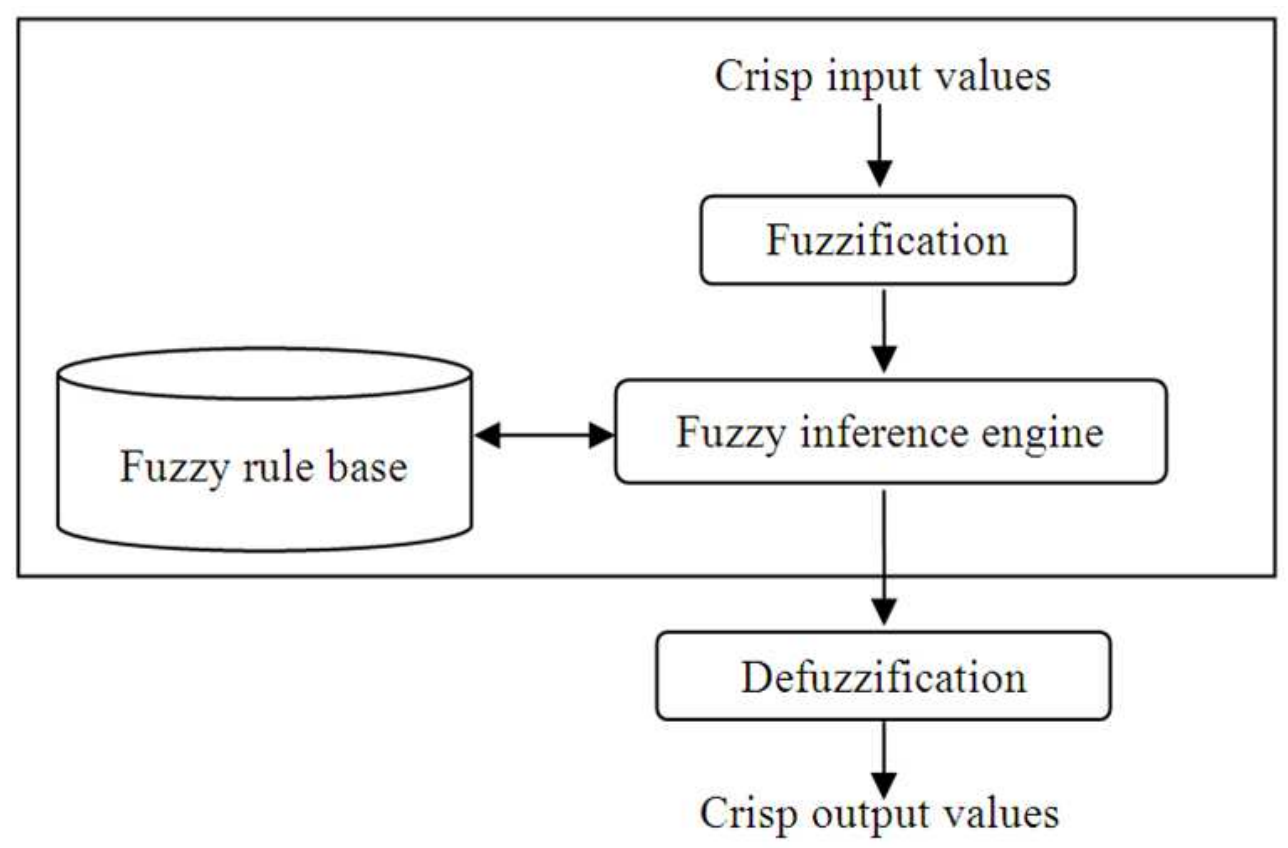

Fig. 1. Fuzzy logic model 
- Fuzzy logic can be blended with conventional control techniques. In many cases fuzzy systems expends the concept of the conventional control techniques and simplify their implementation

Fuzzy logic is based on natural language. The basis for fuzzy logic is the basis for human communication. This observation underpins many of the other statements about fuzzy logic. The following Fig. 1 shows the basic fuzzy logic model.

\subsection{Input Output Membership Functions}

There are two input variables namely WS8 and WS16 were taken for the model. These two are the wind speed at different heights. Five membership functions used for the input variables according to the range of wind speed values. The five input variable membership functions are Very Low (VL), Low (L), Normal (N), High (H) and Very High (VH). The following Table 1 and 2 Shows the input output variable and membership functions.

\section{RESULTS AND DISCUSSION}

One of the important tasks for this developed fuzzy model is the input variable selection. The selection of the input variable determines the fuzzy logic model. The total records of 41621 were used for these input variables. The member function plots for the two input variables wind speed at 8 meter and (WS8) wind speed at 16 meter (WS16m) were depicted in the following Fig. 2-4.

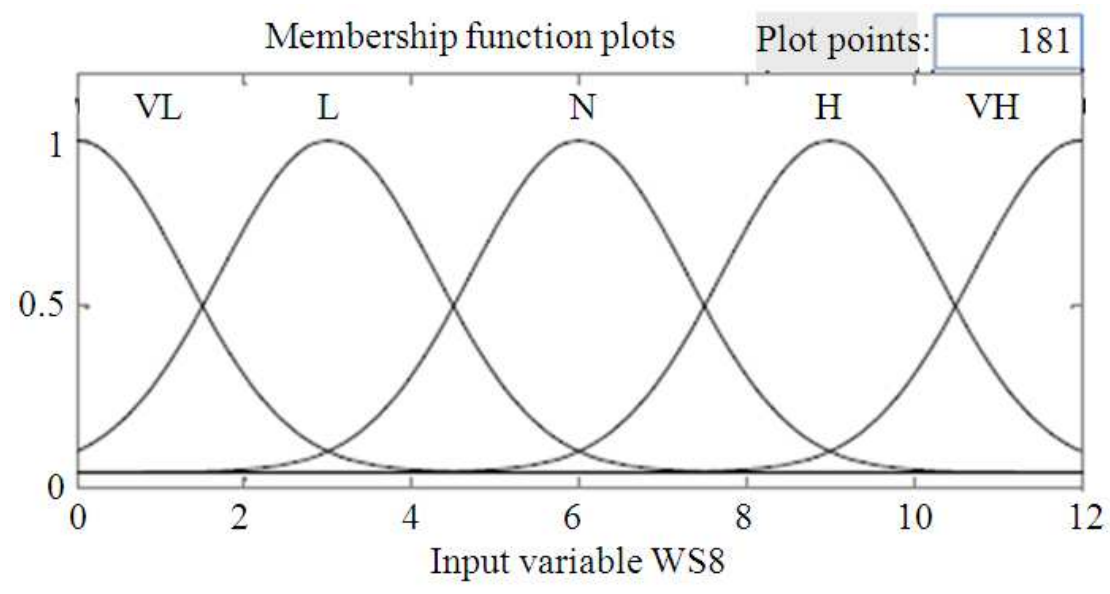

Fig. 2. Input variable WS8

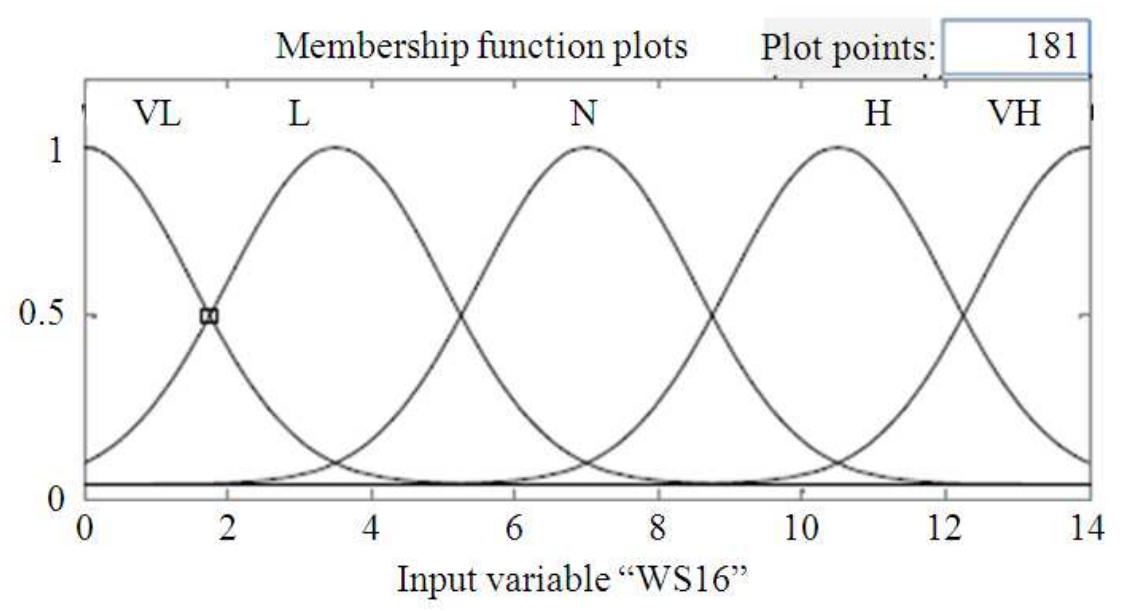

Fig. 3. Input variable WS16 


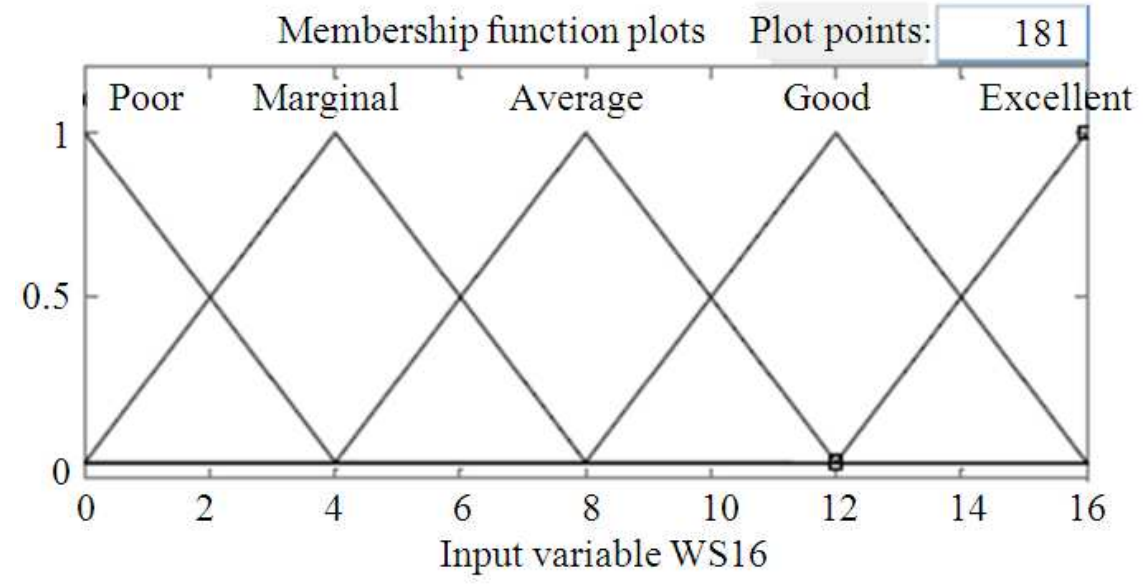

Fig. 4. Output variable WS32

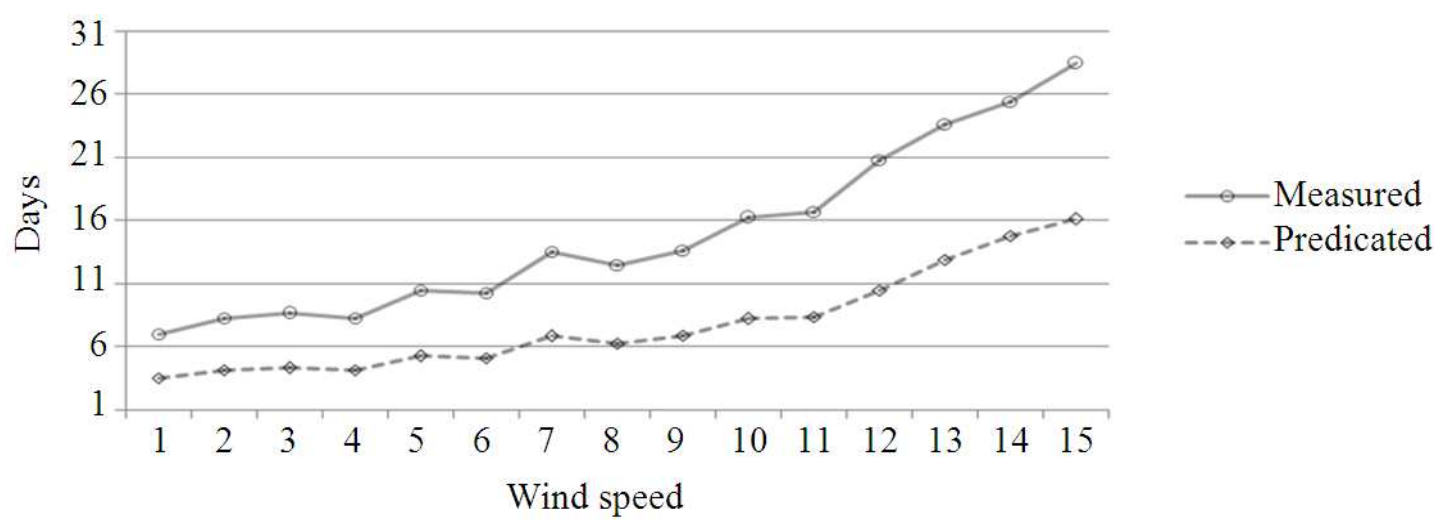

Fig. 5. Wind speed prediction

\subsection{Wind Speed Prediction}

Fuzzy logic modeling reduces the possible difficulties and incorporating the rules for prediction of wind speed. The wind speed at the level of 32 meter in the meteorological tower was predicted using the above fuzzy logic model. The predicted value and the tower data were compared and are shown in the Fig. 5.

\section{CONCLUSION}

A new fuzzy logic model is proposed from the meteorological tower data. This method is based on minimum rule based fuzzy logic. The simulation results shows that from the large amount data utilized to perform better wind speed model. The simulation results illustrate the performance and efficiency of the employed method in predicting the wind speed with high accuracy.

\section{REFERENCES}

Ata, A. and Y. Kocyigit, 2009. An adaptive neuro-fuzzy inference system approach for prediction of tip speed ratio in wind turbines. J. Elect. Elect. Eng., 9: 905-912.

Azouz, M., A. Shaltout and M.A.L. Elshafei, 2010. Fuzzy logic control of wind energy systems. Proceedings of the 14th International Middle East Power Systems Conference, Dec. 19-21 Cairo University, Egypt, pp: 311-311.

Badran, O., E. Abdulhadi and Y. El-Tours, 2011. Fuzzy logic controller for predicting wind turbine power generation. Int. J. Mech. Mater. Eng., 6: 51-60.

Damousis, I.G., M.C. Alexiadis and J.B. Theocharis, 2004. A fuzzy model for wind speed prediction and power generation in wind parks using spatial correlation. IEEE Trans. Energy Convers., 19: 352362. DOI: 10.1109/TEC.2003.821865 
Hocaoglu, F.O., Y. Oysal and M. Kurban, 2009. Missing wind data forecasting with adaptive neuro-fuzzy inference system. Neural Comput. Appli., 18: 207-212.

Hossain, A., A. Rahman, M. Rahman, S.K. Hasan and J. Hossen, 2009. Prediction of power generation of small scale vertical axis wind turbine using fuzzy logic. J. Urban Environ. Eng., 3: 43-51. DOI: 10.4090/juee.2009.v3n2.043051

Javadi, S. and Z. Hojjatinia, 2012. Wind speed modeling and prediction in wind farms using fuzzy logic. Proceedings of the 6th WSEAS International Conference on Computer Engineering and Applications, (EA' 12), Stevens Point, Wisconsin, USA., pp: 98-103.
Mohandes, M., S. Rehman and S.M. Rahman, 2011. Estimation of wind speed profile using Adaptive Neuro-Fuzzy Inference System (ANFIS). Applied Energy, 88: 4024-4032. DOI: 10.1016/j.apenergy.2011.04.015

Perez, A.A., J.J.G. de la Rosa, J.G. Ramiro and J.C.P. Salas, 2010. Genetic Fuzzy learning of local wind conditions. Proceedings of the International Conference on Renewable Energies and Power Quality, Mar. 23-25, Granada, pp: 1-6.

Sreedevi, M. and P.J. Paul, 2011. New intelligent technique for estimating the parameters of wind energy conversion system. Int. J. Soft Comput., 6: 6-10. 